\title{
Impurity Distribution in Germanium-Indium Recrystallized Layer
}

\author{
Hiroe Osafune, and Shigezo Tanaka \\ Semiconductor Division, Nippon Electric Company, Ltd., \\ Kawasaki, Kanagawa \\ Received April 24, 1963
}

The impurity distribution in the $p$-type recrystallized layer made when $n$-type germanium in contact with an indium dot is heated is investigated by means of copper plating, chemical etching and tracer technique. A small amount of ${ }^{114 m} \mathrm{In}-{ }^{114} \mathrm{In}$ or ${ }^{124} \mathrm{Sb}$ is added to high purity indum dot prior to the alloying process. After the alloying process, the regrown indium material on the recrystallized layer is dissolved in conc. $\mathrm{HCl}$, and the crystal polished in a $5^{\circ}$-inclined angle-lapping jig.

The striation patterns that appeared in the recrystallized layer are thought to result from the non-uniformity of the indium distribution. Three types of striation patterns are observed. These depend on the alloying conditions. They are layer-like, stripe and cellular structures. If a $p-n$ junction is exactly parallel with the $\{111\}$ face, the layer-like structure formed is minute and is parallel to the junction. When there is some misorientation from the $\{111\}$ face of a $p-n$ junction, even if it is very slight, stripe structure develops directly from junction face at an angle. At high alloying temperatures and slow cooling rates, a homogeneous region without any striation is made inside the $p-n$ junction with the cellular structures leading from it. The formation mechanism of these striations in the recrystalized layers is also discussed.

\section{Introduction}

The alloyed diodes and transistors which are widely used today as semiconductor elements are made as following ; an $n$-type germanium pellet which is in contact with an indium or indium-gallium dot or dots on its one or both sides is heated at $500 \sim 600^{\circ} \mathrm{C}$ and cooled slowly. A p-region is the regrowth layer which is made by the action of the indium or the indium-gallium left in the regrowth layer, and the junction is made in the vicinity of the interface of the two regions.

According to Pancove ${ }^{1)}$ concerning the impurity concentration in the regrowth region near the $p-n$ junction, resistivity becomes 0.001 ohm-centimeter when pure indium is used and Roverts $^{2)}$ showed that the vicinity of the $p-n$ junction contains $3-4 \times 10^{18}$ indium atoms/cc when pure indium is alloyed at $615^{\circ} \mathrm{C}$. Besides these a number of papers has been published on the striation patterns which appear in the single crystal of germanium, silicon or other compound semiconductors pulled from a melt with Czochralski method, due to segregation of the impurities.

The purpose of this experiment is to see whether the striation pattern due to segregation of the impurity appears in the regrowth layers of germanium when indium is alloyed in it or not, and how the impurity is distributed in the regrowth region. Three methods using copper plating, chemical etching or radio isotopes were adopted in the experiment.

\section{Copper Plating and Chemical Etching Methods}

\subsection{Method of experiment}

The $n$-type germanium used in this experiment has resistivity of $10 \sim 20 \mathrm{ohm}$-centimeter with antimony doped, etch pit of less than $5000 / \mathrm{cm}^{2}$ and crystal orientation of $\langle 111\rangle$ with \pm 1 degree of misorientation. The indium used is $99.99 \%$ pure with $2.4 \mathrm{~mm}$ diameter. The germanium with relatively high resistivity is used in order to avoid an interaction between 
antimony in the germanium and indium, and the crystal orientation of $\langle 111\rangle$ is used because of its most popularity. The alloying was performed in hydrogen atmosphere, and 8 steps of alloying temperature with $50^{\circ} \mathrm{C}$ apart between $300 \sim 650^{\circ} \mathrm{C}$ and 3 cooling speeds of $1.6^{\circ} \mathrm{C} / \mathrm{min}, 13^{\circ} \mathrm{C} / \mathrm{min}$ and $25^{\circ} \mathrm{C} / \mathrm{min}$ were used. The diameter of the re growth region after alloying was approximately $3 \mathrm{~mm}$.

In order to remove the indium which was frozen to the surface of the regrowth region the pellet was soaked in concentrated hydrochloric acid, fastened to a five degree angle lapping jig, lapped with 3000 Mesh carborundum and finished with diamond paste. Some were lapped on one side and the others lapped on four sides to have a shape of pyramid. The regrowth region could be magnified 11.4 times in the direction of the depth alone by lapping in 5 degrees.

$p$-Type regrowth region was then copper plated as shown in Fig. 1 by dropping 2\% $\mathrm{CuSO}_{4}$ solution with a little amount of gelatin added $0.2 \sim 0.3 \mathrm{~mA}$ of current being passed through for $1 \sim 2 \mathrm{sec}$.

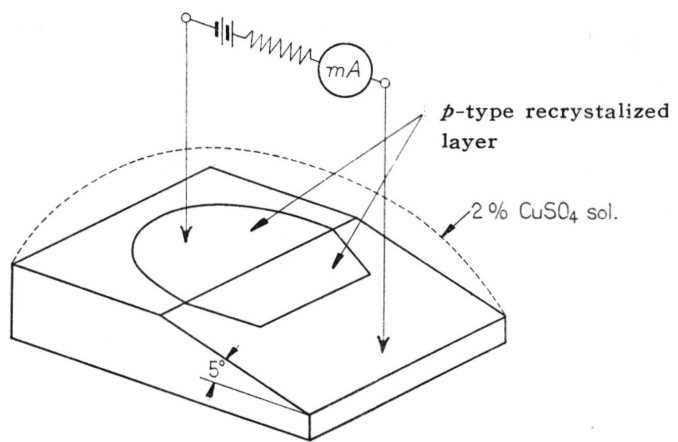

Fig. 1 Apparatus for $\mathrm{Cu}$ plating on the p-type recrystallized layer.

The sample thus copper plated was chemically etched for $30 \mathrm{~min}$. to hr. in a mixed acid; $\mathrm{HNO}_{3}(4): \mathrm{HF}(1): \mathrm{H}_{2} \mathrm{O}(5)$.

\subsection{Result of Experiment}

Photographs of the samples thus plated and etched are shown in Photos 1-12.

It is obvious from these photographs that the plane of $p-n$ junction was formed without being affected by $\{111\}$ plane when the cooling speed was low $\left(1.6^{\circ} \mathrm{C} / \mathrm{min}\right)$ and the alloying temperature was between 300 and $350^{\circ} \mathrm{C}$, and many layers of striation in approximate parallel with the $p-n$ junction plane are alike to annual

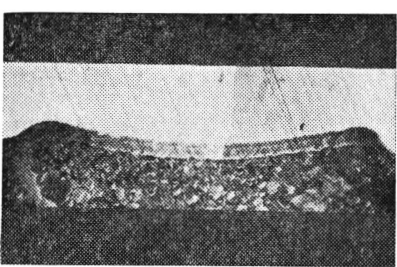

Alloying temp. $3 \mathrm{CO} 0^{\circ} \mathrm{C}$

Cooling rate $1.6^{\circ} \mathrm{C} / \mathrm{min}$

$\times 13$ horizontal

$\times 143$ vertical

Photo $1 \mathrm{Cu}$ plating.

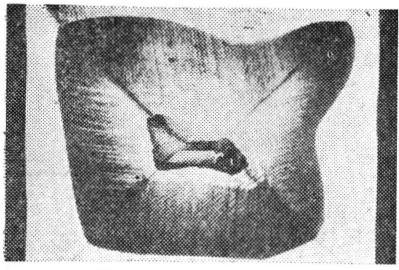

Alloying temp. $450^{\circ} \mathrm{C}$

Cooling rate $1.6^{\circ} \mathrm{C} / \mathrm{min}$

$\times 14$ horizontal

$\times 159$ vertical

Photo $4 \mathrm{Cu}$ plating.

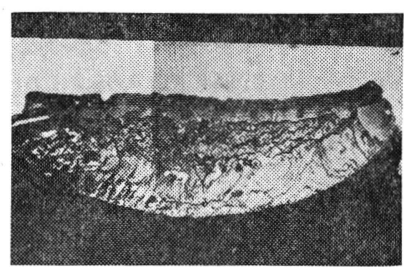

Alloying temp. $350^{\circ} \mathrm{C}$

Cooling rate $1.6^{\circ} \mathrm{C} / \mathrm{min}$

$\times 15$ horizontal

$\times 171$ vertical

Photo $2 \mathrm{Cu}$ plating.

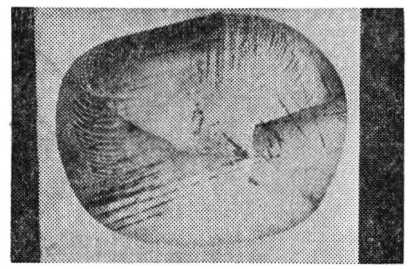

Alloying temp. $500^{\circ} \mathrm{C}$

Cooling rate $1.6^{\circ} \mathrm{C} / \mathrm{min}$ $\times 13$ horizontal $\times 143$ vertical

Photo $5 \mathrm{Cu}$ plating.

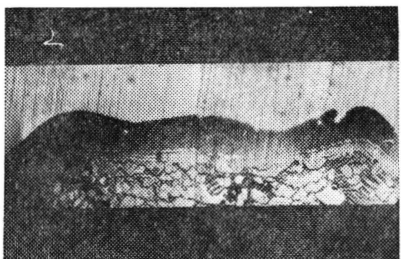

Alloying temp. $400^{\circ} \mathrm{C}$

Cooling rate $1.6^{\circ} \mathrm{C} / \mathrm{min}$

$\times 12$ horizontal

$\times 131$ vertical

Photo $3 \mathrm{Cu}$ plating.

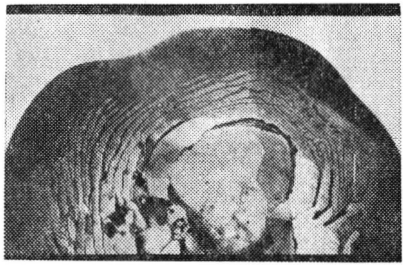

Alloying temp. $600^{\circ} \mathrm{C}$

Cooling rate $1.6^{\circ} \mathrm{C} / \mathrm{min}$ $\times 13$ horizontal $\times 148$ vertical

Photo $6 \mathrm{Cu}$ plating. 


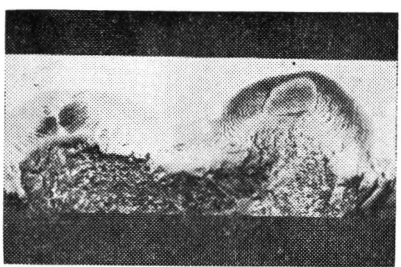

Alloying temp. $400^{\circ} \mathrm{C}$

Cooling rate $13^{\circ} \mathrm{C} / \mathrm{min}$

$\times 12$ horizontal

$\times 139$ vertical

Photo $7 \mathrm{Cu}$ plating.

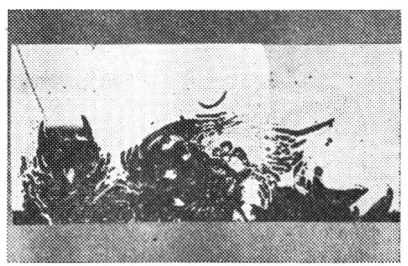

The same sample

to photo 9

$\times 12$ horizontal

$\times 135$ vertical

Photo 10 Chemical etching.

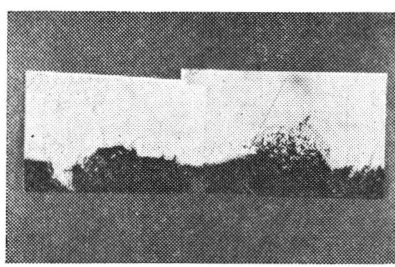

The same sample

to photo 7

$\times 11$ horizontal

$\times 127$ vertical

Photo 8 Chemical etching the same sample to photo 7 .

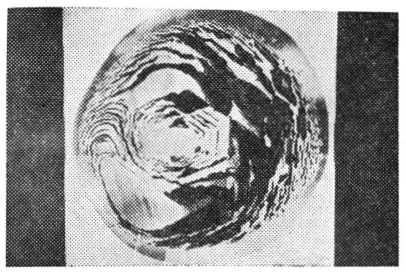

Alloying temp. $600^{\circ} \mathrm{C}$

Cooling rate $13^{\circ} \mathrm{C} / \mathrm{min}$

$\times 8$ horizontal

$\times 95$ vertical

Photo $11 \mathrm{Cu}$ plating.

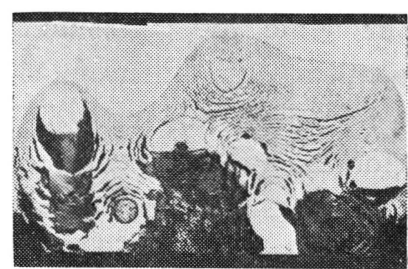

Alloying temp. $500^{\circ} \mathrm{C}$

Cooling rate $13^{\circ} \mathrm{C} / \mathrm{min}$

$\times 12$ horizontal

$\times 139$ vertical

Photo $9 \mathrm{Cu}$ plating.

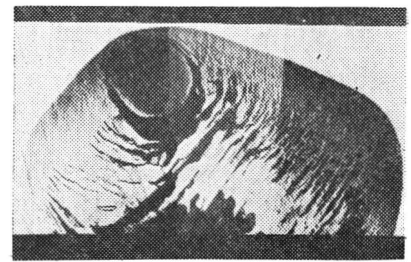

Alloying temp. $600^{\circ} \mathrm{C}$

Cooling rate $25^{\circ} \mathrm{C} / \mathrm{min}$

$\times 13$ horizontal

$\times 151$ vertical

Photo $12 \mathrm{Cu}$ plating. rings of trees. Furthermore 'folds' like the folded mountain range were formed in places of these striations which are thought to veer to the next stage. The difference in concentration of striation formed at this temperature is not thought to be big, however, because the chemical etching did not reveal much of the striations.

When the alloying temperature was raised to about $400^{\circ} \mathrm{C}$, the folded-range-like 'folds' developed to 'stripes' starting from the $p-n$ junction plane and a few 'folds' joined to the 'stripes' were left in the upper part of the regrowth region.

Around $450^{\circ} \mathrm{C}$ of alloying temperature the junction plane parallel to $\{111\}$ plane was formed and layers of striation were formed in complete parallel with the junction plane with extremely narrow spacings between each striation. However, the chemical etching did not reveal them so well and the concentration difference is thought to be small. This region is narrower in the upper part of the regrowth region and it is understood that the growing speed of the crystal of $\{111\}$ plane was smaller than that of any other plane $e^{3)}$. A little discrepancy of the junction plane from the $\{111\}$ plane resulted in a slanting 'stripe' striation from the junction plane and two types of striation were intersecting near the discrepancy.

At alloying temperature above $500^{\circ} \mathrm{C}$ was formed a homogeneous region without any striation within the regrowth region and cellular striation appeared adjacent to this region. The cellular striation pattern became coarser as alloying temperature was raised.

With a faster cooling speed $\left(13^{\circ} \mathrm{C} / \mathrm{min}\right)$ the striation pattern became finer when alloying temperature was low (in the vicinity of $400^{\circ} \mathrm{C}$ ), and the striation-free region narrower when alloying temperature was high (above $600^{\circ}$ ).

With a still faster cooling speed $\left(25^{\circ} \mathrm{C} / \mathrm{min}\right)$ almost no striation appeared when alloying temperature was low and almost no striationfree region could be seen but 'stripe' striation developed directly from the boundary plane instead of cellular striation when alloying temperature was high.

Each of these striation is joined to the surface concave of the regrowth region which has 
finally frozen in unevenness, showing close relationship with the mechanism of the crystal growth. The 'stripe' and the cellular striations were clearly revealed by chemical etching and hence a considerable concentration difference is thought to exist. It can not be seen that there were particularly more dislocations in the region with a higher impurity concentration than any other region.

\subsection{Discussion}

\subsubsection{Origin of Layers of Striation}

Developing Along Junction Plane

It is thought that crystal does not grow continuously but grows intermittently when freezing starts at the interface of the solid and the liquid. This can be explained as following : if the system is in supercooling, and freezing starts at the interface a crystal grows rapidly, the impurity concentration in the crystal being determined by the segregation constant and the impurity concentration in the liquid near the interface increasing rapidly. When this concentration so increases to lower f.p. the crystallization speed becomes much lower and impurities are mostly segregated in the liquid from the solid during freezing; hence the impurity concentration in the slowly crystallized region is lower than that in the rapid one. While the crystallization slowly takes place, the impurities piled up near the interface diffuses into liquid. Its concentration in the liquid near the interface thus decreases, f.p. of the liquid near the interface again rising. On the other hand the temperature of the whole system is falling. This causes constitutional supercooling in the neighbourhood of the interface, resulting a rapid crystal growth, and the impurity concentration becomes higher again because the impurity is not rejected into the liquid during the rapid growth of crystal. Thus it is thought that the crystal grows to make light and shady layers due to the impurity concentration.

\subsubsection{Origin of 'Stripe' Striation De- veloping Aslant from Junction Plane}

Tiller ${ }^{4}$ showed that 'when the crystal grows at the interface of liquid and solid, the direc-
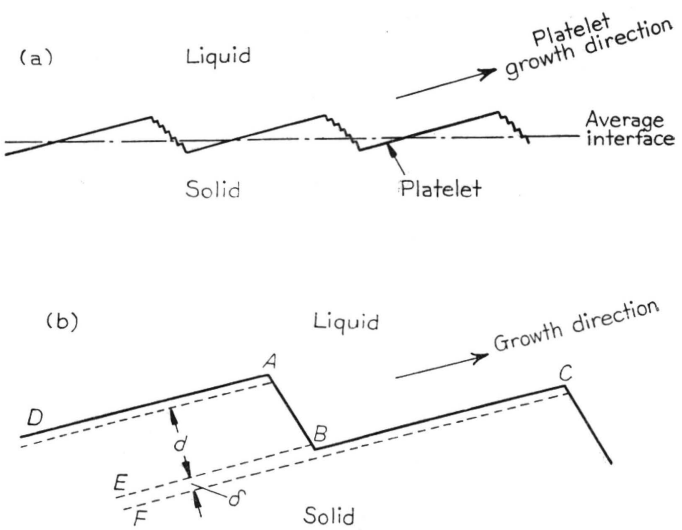

Fig. 2 Schematic representation of the edgewise growth of $\{111\}$ platelet at the solidliquid interface (after W.A. Tiller ${ }^{4}$ )

tion of the crystal growth is not an orthogonal plane to the interface, but a corrugate facet' and he considered a model as shown in Fig. 2 and furthermore he described that since the impurity rejected from $\mathrm{AB}$ facet diffuses less into liquid at $\mathrm{B}$ than at $\mathrm{A}$, the impurity concentration at $\mathrm{B}$ is higher than at $\mathrm{A}$ and more dislocations result in this region. Billing ${ }^{5)}$ showed that in case of diamond lattice structure such as germanium the crystal face grown is $\{111\}$ plane, which grows in $\langle 111\rangle$ direction closest to right angle to the interface.

Taking these results into account the 'stripe' striation developing aslant from the junction plane can be explained by the crystal growth-

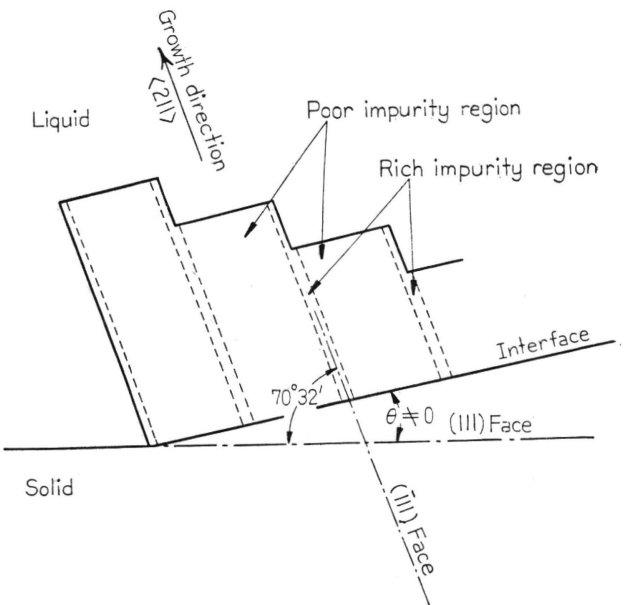

Fig. 3 Schematic representation of the growth direction of recrystallized layer when (111) face is intersected by (111) face. 
from the interface slightly discrepant with \{111\} plane which grows in an angle of $70^{\circ} 32^{\prime}$, the angle between two $\{111\}$ plane (Fig. 3).

\subsubsection{Origin of Striation-free, Homo- geneous Region Inside Junction Plane and Cellular Striation}

According to Tiller ${ }^{4)}$, Bardsley ${ }^{6}$ and others "cellular structure due to constitutional supercooling is formed when impurity concentration is very high such as in Esaki Diodes' and according to Rutter ${ }^{7)}$ and others 'in pulling a single crystal from un-agitated melt, it can be seen that the constitutional supercooling has started by the transition of the entirely homogeneous region to a cellular structural region' and it is also considered in our experiment that the transition from the striation-free, homogeneous region to the cellular striation region shows the states before and after the start of constitutional supercooling.

\section{Radio-Isotope Method}

\subsection{Method of Experiment}

The crystalline axes of germanium and the dimensions of the indium dots used as carrier metal were $\langle 111\rangle$ and $\langle 100\rangle$, and $2.4 \mathrm{~mm}$ in diameter, respectively, for the auto-radiograph, and $\langle 111\rangle$, and 0.9 and $1.5 \mathrm{~mm}$ in diameter, respectively for the measurement with a counter.

The nuclide used for the auto-radiograph was ${ }^{124} \mathrm{Sb}$, for the counter measurement ${ }^{114 m} \mathrm{In}$ ${ }^{114}$ In nuclear isomer, both of chloride diluted with hydrochloric acid solution. Indium dots were coated with either of these solution by repeating dipping in it and drying by an infrared lamp. The chloride was used because the $\mathrm{Cl}_{2}$ or $\mathrm{HCl}$ gas decomposed by atmospheric hydrogen (and reacting with $\mathrm{H}_{2}$ ) improves wetting property of indium to germanium.

Alloying was performed in hydrogen atmosphere at $300 \sim 600^{\circ} \mathrm{C}$ with a constant cooling speed of $13^{\circ} \mathrm{C} / \mathrm{min}$ and then the residual indium was removed in concentrated hydrochloric acid.

In order to analyze the impurity distribution in the junction plane of the regrowth region autoradiograph method was utilized. The dry plate used was Fuji Dry Plate for Auto-radiograph (ET-2E for Strip with $15 \mu$ film thickness) and exposure time was calculated from the following equation which gives for the film a proper exposure, $3 \times 10^{8}$ electrons $/ \mathrm{cm}^{2}$.

$$
\int_{0}^{t_{1}} N d t=\frac{N_{0}}{\lambda}\left[1-e^{-\lambda t_{1}}\right]=3 \times 10^{8}
$$

where $N$ : total number disintegrated

$N_{0}$ : number disintegrated per min at $t=0$

$t_{1}:$ exposure time

$\lambda: 8.0410^{-6} / \mathrm{min}$ (decay constant of ${ }^{124} \mathrm{Sb}$ ) and the average energy of $\beta$ ray was taken as $0.35 \mathrm{MeV}$.

Also in order to avoid blackening due to Russel effect the surface of specimen was coated with collodion solution diluted with about three times alcohol and dried. The film thickness of the collodion coating was approximately $8 \mu$ according to the estimation using the following equation,

$$
\Delta x=\frac{1}{\pi a^{2}} \cdot \frac{g_{c}}{\rho_{c}} \cdot \frac{\Delta v}{v_{1}}
$$

where $\Delta x:$ film thickness

$g_{c}:$ weight of collodion

$\Delta v$ : volume of collodion solution

$\rho_{c}:$ specific gravity of collodion $(=1.64)$

$v_{1}$ : volume of alcohol tether

Then in order to analyze the impurity distribution in the cross section of the regrowth region Geiger-Müller counter was utilized. The reason is that there was a considerable difference in the concentration between one near the junction plane and other at the surface of the regrowth region, the distance between the junction and the surface of the regrowth region being small. This made it difficult to expose the film properly, because the junction plane was not blackened when the regrowth surface was taken as the standard of a proper exposure, while the whole film was blackened when the junction plane was taken as the standard. From this reason the impurity distribution was measured by repeating counting, etching and 
measuring the etched weight of the specimen. The Geiger-Müller counter and the scaler used were manufactured by the Institute of Physical and Chemical Reseach and the etching solution was a mixed acid, $\mathrm{HNO}_{3}(4): \mathrm{HF}(1): \mathrm{H}_{2} \mathrm{O}$ (8) and the etched weight was checked each time.

\subsection{Nuclide Used}

The radioactive antimony used as a tracer consists of less than $10 \%{ }^{122} \mathrm{Sb}$ with a half life of 2.8 days and the rest ${ }^{124} \mathrm{Sb}$ with a half life of 60 days which falls into excited states radiating six different $\beta^{-}$rays $\beta_{1}-\beta_{6}{ }^{8}$. The average energy of the $\beta$ ray is $0.35 \mathrm{MeV}$, maximum $\beta$ particle range $100 \mathrm{mg} / \mathrm{cm}^{2}$ and the electron in each excited state disintegrates in ${ }^{124} \mathrm{Te}$ radiating a $\gamma$ ray with maximum energy of 2.11 $\mathrm{MeV}$. The specific activity during the process is approximately $2.1 \mathrm{mc} / \mathrm{g}$.

The radioactive indium also used as a tracer was a processed radioisotope, ${ }^{114 m}$ In which is a nuclear isomer of ${ }^{114} \mathrm{In} .{ }^{114 m} \mathrm{In}$ disintegrates with a half life of 49 days into ${ }^{114} \mathrm{In}$ radiating a $r$ ray with $0.191 \mathrm{MeV} .{ }^{114}$ In decays with a half life of 72 second and $98 \%$ of the total disintegrates into ${ }^{114} \mathrm{Sn}$ radiating $\beta^{-}$with $1.98 \mathrm{MeV}$ and the rest disintegrates into ${ }^{114} \mathrm{Cd}$ by $k$ electron-capture-decay ${ }^{8)}$. The specific activity during the process is approximately $4.9 \mathrm{mc} / \mathrm{g}$.

\subsection{Result of Experiment}

The absorption curve of ${ }^{114} \mathrm{~m}$ In using aluminium absorption plate is shown in Fig. 4. The steep part of the slope corresponds to the $\beta^{-}$ with $0.71 \mathrm{MeV}$, i.e. Maximum $\beta$ particle range of $250 \mathrm{mg} / \mathrm{cm}^{2}$ and the gentle part of the slope to the $\beta^{-}$with $1.984 \mathrm{MeV}$, i.e. maximum $\beta$ particle range of $950 \mathrm{mg} / \mathrm{cm}^{2}$ and the absorption coefficient is $0.31 \mathrm{~cm}^{2} / \mathrm{mg}$. The flat part of the curve corresponds to the $r$ ray and the background. The thickness of absorption is $26.6 \mathrm{mg} / \mathrm{cm}^{2}$, assuming the maximum thickness of the regrowth region containing ${ }^{114 m} \mathrm{In}$ to be $50 \mu$, but from the graph the effect of the self-adsorption can be neglected, since $98 \%$ of the total is due to the $\beta^{-}$with maximum $\beta$ particle range of $950 \mathrm{mg} / \mathrm{cm}^{2}$.

The impurity distribution in the junction

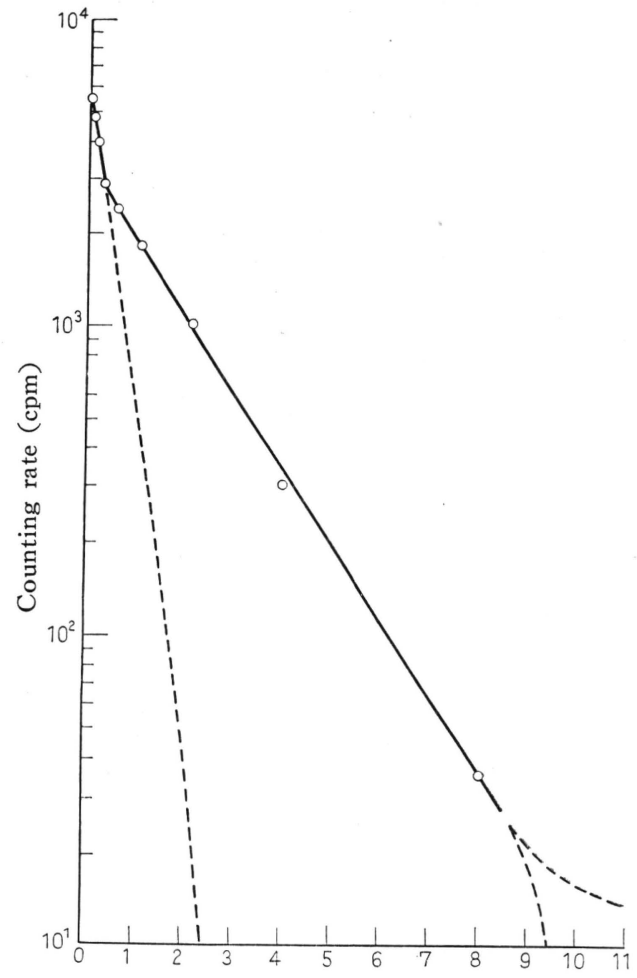

Thickness of $\mathrm{Al}$ absorption plate $\left(\times 10^{3} \mathrm{mg} / \mathrm{cm}^{2}\right)$ Sample : $\mathrm{InCl}_{3}$

Absorption coeff. $u=6.14 \times 10^{-3} \mathrm{~cm}^{2} / \mathrm{mg}$

Fig. 4 Absorption curve of ${ }^{114 \mathrm{~m}} \mathrm{In}$ in aluminum.

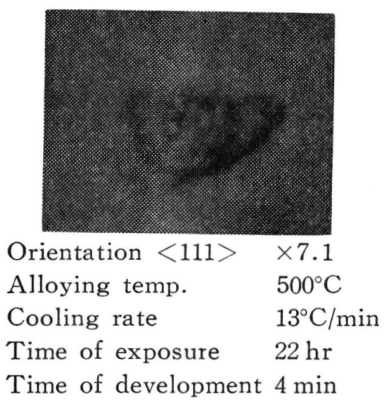

Photo $13{ }^{124} \mathrm{Sb}$ doped auto-radiograph.

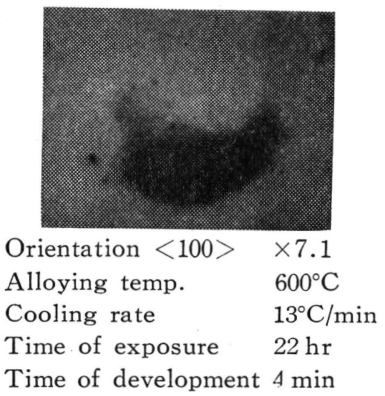

Photo $14{ }^{124} \mathrm{Sb}$ doped auto-radiograph. 
Table 1 The Method of Calculation to Obtain the Number of Atoms per Cubic Centimeter

\begin{tabular}{|c|c|c|c|c|c|c|c|c|c|c|c|}
\hline $\begin{array}{l}\text { cpm } \\
\text { when } \\
\text { meas- } \\
\text { ured } \\
\text { 1) }\end{array}$ & $\begin{array}{c}\text { cpm } \\
\text { of } \\
\text { back } \\
\text { ground } \\
2)\end{array}$ & $\begin{array}{c}\text { cpm with } \\
\text { back ground } \\
\text { subtracted } \\
\text { 3) }\end{array}$ & $\begin{array}{l}\text { cpm/ } \\
\text { (back } \\
\text { scat- } \\
\text { tering } \\
\text { coeff.) } \\
4 \text { ) }\end{array}$ & $\begin{array}{l}\text { cpm when } \\
\text { alloyed } \\
\text { 5) }\end{array}$ & $\begin{array}{c}\text { weight } \\
\text { loss } \\
(\mathrm{mg})\end{array}$ & $\left|\begin{array}{c}\text { depth/ } \\
0.1 \mathrm{mg} \\
(\mu) \\
6)\end{array}\right|$ & $\begin{array}{c}\text { cpm } \\
\text { difference }\end{array}$ & $\begin{array}{c}\mathrm{cpm} / 0.1 \mathrm{mg} \\
7)\end{array}$ & $\begin{array}{c}\mathrm{cpm} / \\
0.1 \mathrm{mg}\end{array}$ & \begin{tabular}{|} 
(num- \\
bers of \\
atoms) \\
$/ 0.1 \mathrm{mg}$ \\
$\times 10^{5}$ \\
$8)$
\end{tabular} & $\begin{array}{l}\text { (numbers } \\
\text { of atoms) } \\
/ 1 \mathrm{cc} \\
\times 10^{11} \\
9 \text { ) }\end{array}$ \\
\hline 342.6 & 21.10 & $321.5 \pm 5.9$ & 257.2 & $267.5 \pm 4.9$ & 0 & 0 & $132.8 \pm 7.3$ & $66.4 \pm 3.7$ & 259.4 & 263.9 & $399.9 \pm 18.2$ \\
\hline 179.4 & 20.53 & $158.87 \pm 4.3$ & 127.1 & $134.7 \pm 3.7$ & 0.2 & 0.5 & $25.2 \pm 5.8$ & $5.04 \pm 1.2$ & 19.4 & 20.0 & $25.0 \pm 5.8$ \\
\hline 149.7 & " & $129.17 \pm 3.9$ & 103.3 & $109.5 \pm 3.3$ & 0.7 & 1.8 & $6.5 \pm 5.4$ & $2.17 \pm 1.8$ & 8.48 & 8.6 & $10.8 \pm 9.0$ \\
\hline 142.0 & " & $121.47 \pm 3.8$ & 97.17 & $103.0 \pm 3.2$ & 1.0 & 2.6 & $8.83 \pm 5.3$ & $2.94 \pm 1.8$ & 11.48 & 11.7 & $14.6 \pm 8.8$ \\
\hline 130.5 & 20.49 & $110.01 \pm 3.6$ & 88.01 & $94.17 \pm 3.1$ & 1.3 & 3.3 & $16.69 \pm 5.1$ & $2.67 \pm 0.72$ & 10.43 & 10.6 & $13.2 \pm 3.6$ \\
\hline 111.0 & " & $90.51 \pm 3.4$ & 72.41 & $77.48 \pm 2.9$ & 2.0 & 5.1 & $64.73 \pm 4.0$ & $2.81 \pm 0.18$ & 10.97 & 11.2 & $14.0 \pm 0.9$ \\
\hline 35.5 & 21.01 & $14.49 \pm 2.0$ & 11.59 & $12.75 \pm 1.9$ & 4.3 & 11.1 & $0.53 \pm 2.7$ & $0.26 \pm 0.35$ & 1.02 & 1.0 & $1.3 \pm 6.7$ \\
\hline 34.9 & $" \prime$ & $13.89 \pm 1.9$ & 11.11 & $12.22 \pm 1.8$ & 4.5 & 11.6 & $0.61 \pm 2.7$ & $0.31 \pm 0.35$ & 1.21 & 1.2 & $1.5 \pm 6.7$ \\
\hline 34.2 & $" \prime$ & $13.19 \pm 1.9$ & 10.55 & $11.61 \pm 1.8$ & 4.7 & 12.1 & $4.44 \pm 2.6$ & $0.25 \pm 0.15$ & 0.97 & 0.99 & $1.2 \pm 0.7$ \\
\hline 28.9 & 21.04 & $7.86 \pm 1.8$ & 6.29 & $7.17 \pm 1.7$ & 6.5 & 16.7 & $1.73 \pm 2.6$ & $0.16 \pm 0.20$ & 0.63 & 0.64 & $0.8 \pm 1.0$ \\
\hline 27.0 & $" \prime$ & $5.96 \pm 1.7$ & 4.77 & $5.44 \pm 1.6$ & 7.6 & 19.5 & $1.55 \pm 2.3$ & $0.11 \pm 0.09$ & 0.43 & 0.44 & $0.55 \pm 0.45$ \\
\hline 25.3 & $" \prime$ & $4.26 \pm 1.7$ & 3.41 & $3.89 \pm 1.6$ & 9.0 & 23.1 & & & & & \\
\hline
\end{tabular}

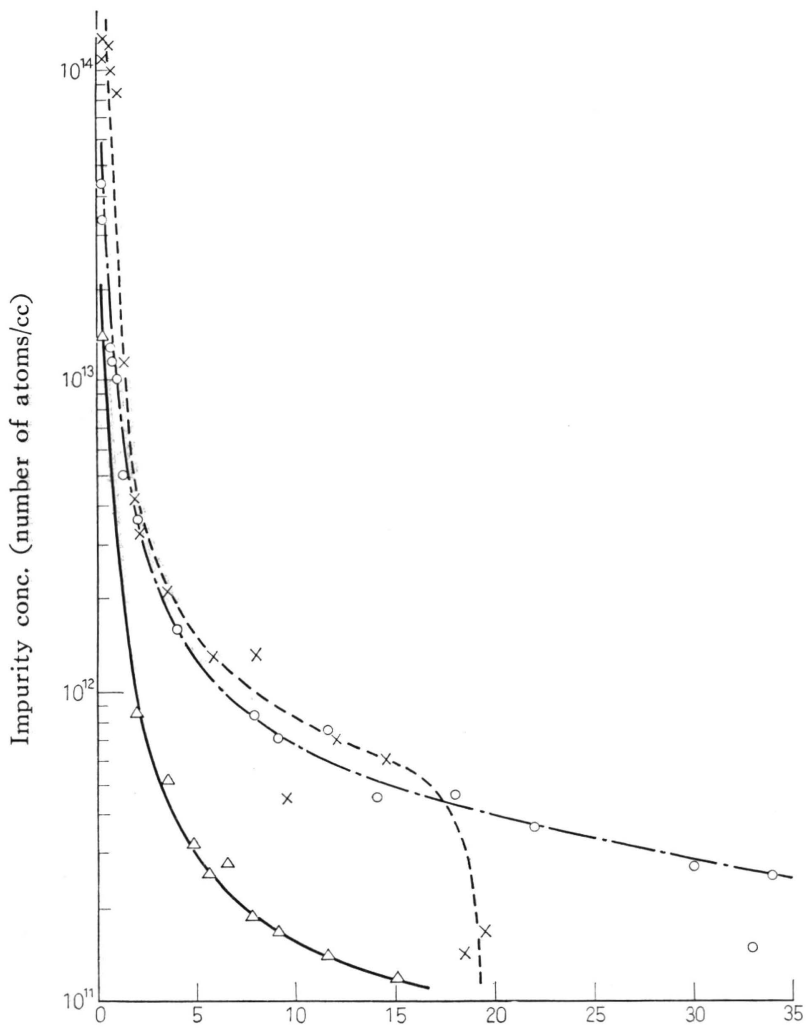

The depth from the surface of the recrystallized layer $(\mu)$ Alloying temp. In dot size

$\begin{array}{lll}\cdots \times \cdots \cdots \cdots \times \cdots & 400^{\circ} \mathrm{C} & 0.9 \mathrm{~mm} \phi \\ -\bigcirc-\cdots-\bigcirc- & 500^{\circ} \mathrm{C} & 0.9 \mathrm{~mm} \phi \\ -\triangle & 600^{\circ} \mathrm{C} & 0.9 \mathrm{~mm} \phi\end{array}$

Fig. 5 (A) Relation between the impurity concentration and the depth from the surface of the recrystallized layer. 
plane obtained by using ${ }^{124} \mathrm{Sb}$ and auto-radiograph is shown in Photos 13 and 14. From these photographs it can be seen that when the crystal axis of germanium is $\langle 111\rangle{ }^{124} \mathrm{Sb}$ is piled up around the regrowth region and around the un-wetted spots and when the axis is $\langle 100\rangle$ ${ }^{124} \mathrm{Sb}$ is distributed uniformly in the regrowth region.

Impurity distribution analysis in the cross section using ${ }^{114 \mathrm{~m}} \mathrm{In}-{ }^{114} \mathrm{In}$ and Geiger-Müller counter is carried out in the order as shown in Table 1. Notes.

1) Time spent for measurement of the sample : $10 \mathrm{~min}$.

2) Time spent for measurement of the background : $100 \mathrm{~min}$.

3) $\frac{M}{T_{1}}-\frac{m}{T_{2}} \pm \sqrt{\frac{M}{T_{1}{ }^{2}}+\frac{m}{T_{2}{ }^{2}}}$ is used for calculation

where $M$ : number of counts of the sample $m$ : number of counts of the background

$T_{1}$ : time spent for measurement of sample

$T_{2}$ : time spent for measurement of background

4) calculated with backward scattering coefficient taken as 1.25

5) $N=N_{0} e^{-\lambda t}$ is used for calculation where $\lambda=9.88 \times 10^{-6} / \mathrm{min}$ for ${ }^{114 \mathrm{~m}} \mathrm{In}$

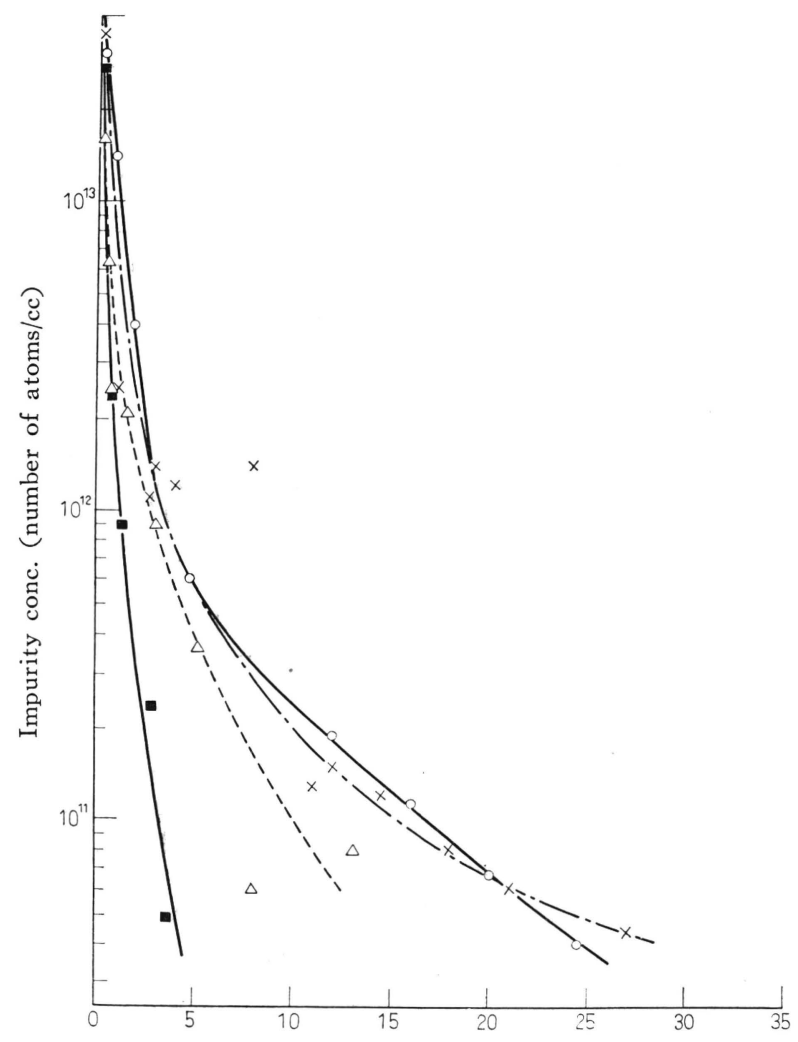

The depth from the surface of the recrystallized layer $(u)$

$\begin{array}{ccc} & \text { Alloying temp. } & \text { In dot size } \\ - & 350^{\circ} \mathrm{C} & 1.5 \mathrm{~mm} \phi \\ \cdots \triangle \cdots \cdots \cdots \cdots & 450^{\circ} \mathrm{C} & 1.5 \mathrm{~mm} \phi \\ -\times-\times- & 500^{\circ} \mathrm{C} & 1.5 \mathrm{~mm} \phi \\ -\bigcirc- & 600^{\circ} \mathrm{C} & 1.5 \mathrm{~mm} \phi\end{array}$

Fig. 5 (B) Relation between the impurity concentration and the depth from the surface of the recrystallized layer. 
$N$ : total number disintegrated

$N_{0}$ : number disintegrated per minute at $t=0$

6) etched depth calculated with assuming dimensions of germanium sample to be $6 \times 6 \times 1 \mathrm{~mm}$ each

7) counting efficiency of ${ }^{114 \mathrm{~m}} \mathrm{In}$ of GeigerMüller counter in the sample holder is $25.6 \%$

8) calculated from $-\frac{d N}{d t}=\lambda N$

9) converted into number of atoms per 1 c.c. from the depth per $0.1 \mathrm{mg}$ and alloyed area $\left(4.5 \mathrm{~mm}^{2}\right)$

From Table $1^{114 \mathrm{~m}} \mathrm{In}$ atoms/c.c. is plotted against the distance from the surface of the regrowth region and shown in Fig. $5(\mathrm{~A})$ and (B). The impurity distribution in the cross section is similar to the well known normal freezing curve by $\mathrm{Pfann}^{8)}$, and the impurity concentration near the $p-n$ junction plane and that at the surface of regrowth region are different by about three orders of magnitude.

\subsection{Discussion}

From the results obtained with the radio isotope technique and copper plating method mentioned above, the impurity distributions in the regrowth region are assumed to be as shown in Fig. 6. In case of layer-like and stripe structures, i.e., at relatively low alloying temperature, schematic representation of impurity distribution perpendicular to the junction plane appears as shown in Fig. 6-(a). In this case if the specimen is cut along the direction of some striation, the impurity distribution appears as shown in Fig. 6-(b). In case of cellular structures, i.e., at relatively high alloying temperatures and slow cooling rates, a homogeneous region without any striation is made inside the $p^{-n}$ junction and cellular structures follow as shown in Fig. 6-(c).

\section{Summary}

The results described above can be summarized as following:

4.1 The striation patterns are thought to

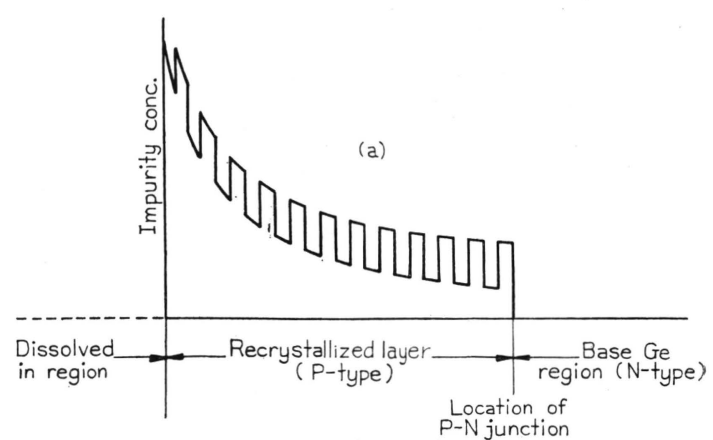

(a) Case of layer-like and stripe structures

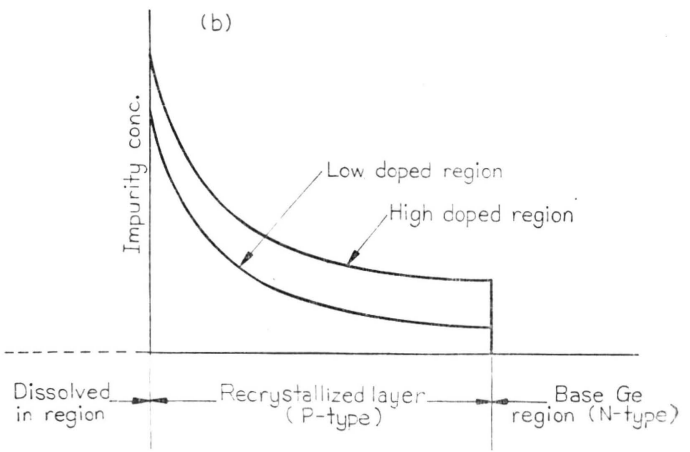

(b) Case of cut paralle! to stripe structures

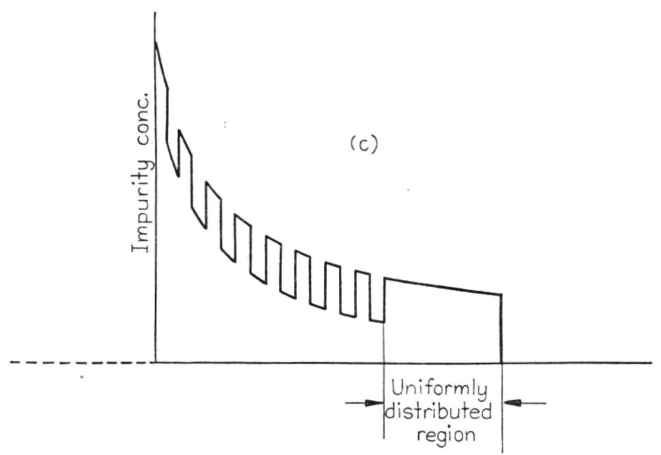

(c) Case of cellular structures

Fig. 6 Schematic representation of impurity distribution in the recrystallized layer.

result from the segregation of indium because the concentrated portion of Copper deposition after Copper plating agrees very well with the deeply etched portion after chemical ething.

4.2 These striations can be classified into three categories: 'layer' striation formed at 300 $\sim 350^{\circ} \mathrm{C}$, 'stripe' striation formed at $400 \sim 500$ ${ }^{\circ} \mathrm{C}$ or when cooled rapidly, and cellular striation formed at above $500^{\circ} \mathrm{C}$. The variation of indium concentration in the 'layer' striation is small 
but those in the 'stripe' and cellular striation are considerably large.

4.3 The higher the alloying temperature is, the higher the concentration is and the coarser the striation patterns are.

4.4 It can not be seen that there are more dislocations in the region with a higher impurity concentration as Tiller showed.

4.5 It is shown in the radio isotope experiment that the impurity distributes uniformly in the junction plane when the crystal axis is $\langle 100\rangle$ and it more concentrated around the regrowth region than when the crystal axis is $\langle 111\rangle$.

4.6 The impurity distribution curve in the cross section is very similar to Pfann's normal freezing curve, and the concentration increases monotonically from the junction plane to the surface of the regrowth region, the difference of the concentrations between those at these two planes being approximately three orders of magnitude.

4.7 The impurity distribution in the regrowth region obtained from the results of radio isotope and copper plating is as shown in Fig. 6.

4.8 As shown above the mechanism of regrowth of germanium-indium is sensitive to the alloying temperature, configuration of the interface, discrepancy with the crystal axis, cooling speed, etc.

4.9 As a result it can be said that the alloying temperature and the cooling speed should be chosen such as to form the $p-n$ junction plane perfectly parallel to $\{111\}$ plane or to form a striation free, homogeneous region within the regrowth region and avoid such a condition that forms striations developing directly from the junction plane.

\section{Acknowledgement}

The authors wish to express their appreciation to Mr. Shiro Otani for his many useful guidance on the radio isotope technique. The authors also wish to thank Dr. Yasuo Matsukura for his precious suggestions.

\section{Literature :}

1) J.I. Pankove, RCA Review 15, 75 (1954).

2) F.E. Roberts, Solid State Electronics 2, 8 (1961).

3) V.O. Yesin, "The Physics of Metals and Metallography" 10 (1960).

4) W.A. Tiller, J. Appl. Phys. 29, 611 (1958).

5) E. Billig, Proc. of Royal Society (of London) 229, 346 (1955).

6) W. Bardsley et al., Solid State Electronics 3, 142 (1961).

7) J.W. Rutter and B. Chalmers, Canadian Journal of Physics, 31 (1953).

8) "Radio Isotope Handbook", ed. by Japan Radio Isotope Association.

9) W.G. Pfann, Journal of Metals, Transaction AIME 7, 747 (1952). 